\title{
FLUTUAÇÃO POPULACIONAL DE ADULTOS DE Anastrepha fraterculus (Wied.) EM CULTIVO PROTEGIDO E CONVENCIONAL DE VIDEIRA ${ }^{1}$
}

\author{
GERALDO CHAVARRIA ${ }^{2}$, MARCELO ZART ${ }^{3}$, MARCOS BOTTON ${ }^{4}$, \\ HENRIQUE PESSOA DOS SANTOS ${ }^{5}$, GILMAR ARDUÍNO BETTIO MARODIN ${ }^{6}$
}

RESUMO - A mosca-das-frutas sul-americana, Anastrepha fraterculus (Wiedemann, 1830) (Diptera: Tephritidae), é considerada praga-chave das fruteiras de clima temperado na região Sul do Brasil. No entanto, poucas informações encontram-se disponíveis quando a espécie está associada à cultura da videira. Neste trabalho, foi avaliado o efeito da cobertura plástica sobre a população de adultos de $A$. fraterculus durante o ciclo de cultivo da videira cv. Moscato Giallo. O experimento foi conduzido nos ciclos de 2005/06 e 2006/07, em vinhedo comercial localizado em Flores da Cunha-RS (latitude $29^{\circ} 06^{\prime}$ sul, longitude $51^{\circ} 20^{\prime}$ oeste e altitude de $\left.541 \mathrm{~m}\right)$, coberto com plástico impermeável tipo ráfia $(160 \mu \mathrm{m})$ de 12 fileiras com $35 \mathrm{~m}$, deixando-se cinco fileiras sem cobertura (controle). Os adultos foram monitorados nas duas áreas com armadilhas McPhail, utilizando-se como atrativo de proteína hidrolisada (BioAnastrepha®) a $5 \%$, no período de outubro a abril, nos dois ciclos. O pico populacional da espécie, nos dois ciclos, foi observado no período de maturação da uva. Não foram registradas diferenças significativas nas capturas entre as áreas, concluindo-se que a cobertura plástica não afeta a mobilidade e a flutuação populacional de A. fraterculus em cultivo protegido de videira.

Termos para Indexação: Monitoramento, plasticultura, Vitis vinifera, moscas-das-frutas.

\section{Anastrepha fraterculus (Wied.) ADULT SEASONAL FLUCTUATION IN PLASTIC COVERING AND CONVENTIONAL GRAPEVINE CULTIVATION}

\begin{abstract}
The South American Fruit Fly Anastrepha fraterculus (Wiedemann, 1830) (Diptera: Tephritidae) is one of the most important pests of temperate fruits in Southern Brazil. Little information regarded to pest damage is available when this insect is associated with vineyards. In this work was evaluated the plastic cover effect on seasonal fluctuation of $A$. fraterculus adults in vineyards of cv. Moscato Giallo. The experiment was conducted on 2005/06 and 2006/07 seasons in a vineyard located in Flores da Cunha, RS (latitude $29^{\circ} 06^{\prime}$ 'South, longitude $51^{\circ} 20^{\prime}$ 'West and altitude $541 \mathrm{~m}$ ), covered with an impermeable plastic cloth $(2.65 \mathrm{~m} \mathrm{x} 160 \mu \mathrm{m})$, in 12 rows with $35 \mathrm{~m}$, with five rows left uncovered (control). Adults were monitored in two areas with McPhail traps using 5\% hydrolyzed protein (BioAnastrepha ${ }^{\circledR}$ ) from October to April in both seasons. No significative differences were observed in A. fraterculus catches among cover and conventional system, concluding that plastic covering does not cause influence in mobility and seasonal fluctuation of $A$. fraterculus in grapevine cultivation.
\end{abstract}

Index Terms: Monitoring, plasticulture, Vitis vinifera, fruit flies.

\footnotetext{
'(Trabalho 206-08). Recebido em: 28-11-2008. Aceito para publicação em: 04-08-2008.

${ }^{2}$ Eng. Agr ${ }^{\circ}$ Prof. Dr. Fisiologia das Plantas Cultivadas, Universidade de Passo Fundo, Passo Fundo-RS. e-mail: geraldochavarria@upf.br ${ }^{3}$ Eng. Agr ${ }^{\circ}$ Mestrando em Agronomia, área de concentração em Entomologia. Universidade Estadual Paulista (FCAV/UNESP), Via de acesso Paulo Donato Castellane, s/n, CEP: 14884-900, Jaboticabal-SP. E-mail: marcelo_zart@yahoo.com.br

${ }^{4}$ Eng. Agr ${ }^{\circ}$ Dr. Pesquisador Embrapa Uva e Vinho, Cx. Postal 130, 95700-000, Bento Gonçalves-RS., e-mail: marcos@cnpuv.embrapa.br ${ }^{5}$ Eng. Agr ${ }^{\circ}$ Dr. Pesquisador Embrapa Uva e Vinho, Cx. Postal 130, 95700-000, Bento Gonçalves-RS., e-mail: henrique@cnpuv.embrapa.br ${ }^{6}$ Eng. Agr ${ }^{\circ}$ Professor Dr. Departamento de Horticultura, Universidade Federal do Rio Grande do Sul, Cx. Postal 91540-000, Porto Alegre-RS. e-mail: marodin@ufrgs.br
} 


\section{INTRODUÇÃO}

O uso da cobertura plástica na cultura da videira tem sido uma prática crescente no cultivo de uvas de mesa, com o objetivo de reduzir os prejuízos causados por granizos e proteger do ataque de pássaros (Schuck et al., 2004). Nos últimos anos, entretanto, essa prática vem sendo ampliada também para as uvas destinadas à vinificação (Santos, 2005). Dentre as vantagens registradas nesse sistema de produção, destacam-se a redução significativa na aplicação de fungicidas e a melhoria da qualidade do mosto, o que pode viabilizar o cultivo orgânico de videiras em regiões com excesso de precipitação pluvial (Chavarria et al., 2007a).

A mosca-das-frutas sul-americana, Anastrepha fraterculus (Wiedemann, 1830) (Diptera, Tephritidae), é considerada uma das principais pragas de fruteiras de clima temperado no Estado do Rio Grande do Sul (Salles, 1998; Kovaleski \& Ribeiro, 2002), principal polo produtor de uvas para processamento do Brasil (Mello, 2007). Na cultura da videira, não existe histórico evidente de perdas relacionadas à mosca-das-frutas, porém relatos de sua presença na cultura em parreirais da região de Bento Gonçalves evidenciam uma constante preocupação de controle pelos produtores (Botton et al., 2003; Zart, 2008). Soria (1985) e Zart (2008) informam que a mosca-das-frutas pode danificar bagas ainda verdes de videiras européias (Vitis vinifera L.), podendo acarretar na queda das mesmas. Botton et al. (2003) destacam que o dano depende principalmente da cultivar e do destino da produção. Em uvas de mesa, o ataque do inseto compromete de forma direta a comercialização, o que pode restringir a exportação por se tratar de praga com importância quarentenária para países importadores (Duarte \& Malavasi, 2000). Além disso, a injúria causada pelo inseto pode servir de "porta de entrada" para doenças, reduzindo a qualidade do produto final (Sela et al., 2005).

No sistema convencional de cultivo (sem cobertura), o controle do inseto tem sido feito basicamente com aplicações de inseticidas fosforados, o que pode resultar na presença de resíduos e no desequilíbrio do sistema, aumentando o ataque de pragas secundárias, com destaque para ácaros fitófagos (Barros et al., 2007).

No que diz respeito à incidência da moscadas-frutas em videira cultivada com cobertura plástica, ainda não existem informações disponíveis que auxiliem os produtores a definir o manejo da praga nestas condições. É conhecido que a abundância da mosca-das-frutas nos pomares é correlacionada diretamente com a disponibilidade de hospedeiros alternativos localizados próximos ao cultivo (RonchiTeles \& Silva, 2005). Porém, a dinâmica populacional da praga pode ser regulada pelas variáveis climáticas com destaque para a precipitação pluvial, umidade relativa, temperatura e velocidade do vento (Raga et al., 1996; Garcia \& Corseuil, 1999). Dentre estas variáveis climáticas, a temperatura tem sido mencionada como a de maior efeito sobre a população de $A$. fraterculus (Garcia \& Corseuil, 1998; Taufer et al., 2000). Todavia, Salles (1995) afirma que a flutuação populacional da mosca-das-frutas não obedece a um padrão, pois se observam variações significativas entre anos, regiões e locais.

Como a cobertura plástica pode atuar como barreira física e/ou alterar as condições micrometeorológicas do vinhedo, neste trabalho, foi avaliado o efeito de tal prática sobre a população de adultos de $A$. fraterculus em videira para processamento.

\section{MATERIAL E MÉTODOS}

O experimento foi conduzido nos anos agrícolas de 2005/06 e 2006/07, em vinhedo localizado no município de Flores da Cunha-RS, distrito de Mato Perso (latitude $29^{\circ} 06^{\prime}$ sul, longitude $51^{\circ} 20^{\prime}$ oeste e altitude de $541 \mathrm{~m}$ ). A cultivar utilizada foi a Moscato Giallo ( $V$. vinifera L., clone VCR1), implantada na área em 1997, enxertada sobre Kobber 5BB, no espaçamento de 3,0 x 0,9 m (3.703 plantas por ha). As plantas foram conduzidas em "Y", dispostas por fileiras de 35 metros na direção nordeste-sudoeste, com podas mistas, deixando varas de 6-8 gemas e esporões de duas gemas. $\mathrm{O}$ vinhedo foi dividido em duas áreas: uma constituída de 12 fileiras cobertas na linha de cultivo com lonas plásticas trançadas de polipropileno transparentes, impermeabilizadas e de baixa densidade (160 $\mu \mathrm{m}$ de espessura), e largura de 2,65 metros; e na segunda área, mantiveram-se cinco fileiras descobertas, cujas linhas centrais foram consideradas como testemunha. As coberturas ficaram a uma altura de $\pm 100 \mathrm{~cm}$, em relação à posição central do dossel vegetativo, e $\pm 20 \mathrm{~cm}$ em cada extremidade, constituindo um V invertido sobre o dossel em Y.

$\mathrm{O}$ microclima foi avaliado por medições de temperatura e umidade relativa do ar (psicrômetros de pares termoelétricos); velocidade do vento (anemômetro de conchas) e radiação fotossinteticamente ativa $(400-700 \mathrm{~nm}$, barras de $1,20 \mathrm{~m}$ equipadas com cinco células fotovoltaicas ligadas em série), nas áreas com e sem cobertura plástica, na altura do dossel vegetativo. Todos os sensores da área experimental foram conectados a dois sistemas de aquisição de dados (CR10 e CR21X, Campbell $\left.{ }^{\circledR}\right)$. Ambos os 
sistemas foram programados para efetuar leituras a cada minuto, e médias, a cada 30 minutos.

A interferência da cobertura na incidência de radiação no espectro de 300 a $750 \mathrm{~nm}$ no dossel vegetativo também foi avaliada através de cinco medições com espectrorradiômetro (marca Licor; modelo LI1800) nos dias 11-01-06, 13-02-06, 06-03-06, 19-0107 e 28-03-07 e obtida média aritmética.

Para o monitoramento da mosca-das-frutas, nos períodos de outubro a abril dos ciclos de 2005/06 e 2006/07, em cada área, foram instaladas quatro armadilhas McPhail (base amarela) contendo solução de proteína hidrolisada (BioAnastrepha $\left.{ }^{\circledR}\right)$, diluída a $5 \%$, as quais foram avaliadas semanalmente. Em cada avaliação, os insetos capturados foram identificados de acordo com Zuchi (2000), contados, e a solução atrativa, trocada. Com os dados das coletas semanais, foi calculado o número de mosca/armadilha/ dia (MAD), considerando-se como nível de controle valores acima de um MAD (Botton et al., 2003).

Durante o ciclo da cultura, não foi realizada nenhuma aplicação de inseticida nas áreas avaliadas (coberta e descoberta).

$\mathrm{Na}$ análise estatística, utilizou-se o programa $\mathrm{R}$ ( R, 2007), sendo que os dados de microclima (temperaturas média, mínima e máxima do ar; umidade relativa do ar; radiação fotossinteticamente ativa e velocidade do vento) foram pareados, e as diferenças entre ambos os tratamentos foram analisadas por regressão linear. A significância do coeficiente angular das equações resultantes foi avaliada pelo teste t. $\mathrm{Na}$ análise dos dados de radiação fotossinteticamente ativa e velocidade do vento, o intercepto foi fixado em zero, pois quando a medida externa for nula, a interna deve também ser obrigatoriamente nula. Contudo, para as variáveis de flutuação da população de mosca-das-frutas e de interferência da cobertura sobre o espectro de radiação solar, os valores foram transformados em $\sqrt{x+1}$ e arco do seno, respectivamente, e submetidos à análise de variância (ANOVA), e as médias, comparadas pelo teste de Tukey, ao nível de $5 \%$ de probabilidade de erro.

\section{RESULTADOS E DISCUSSÃO}

Na avaliação microclimática realizada nos dois ciclos, pôde-se observar, na área coberta, um aumento na temperatura do ar, sobretudo nas temperaturas máximas, pouca interferência na umidade relativa do ar e reduções da radiação fotossinteticamente ativa e velocidade do vento (Tabela 1). Cardoso et al. (2008) destacam que a cobertura plástica sobre o vinhedo impõe um microclima diferenciado se comparada ao cultivo convencional.
No primeiro ano de avaliação (ciclo 2005/2006), foram coletadas 535 e 701 adultos de $A$. fraterculus nas áreas com e sem cobertura plástica, respectivamente. Embora tenha ocorrido redução $(-23,7 \%)$ na captura de moscas sob o cultivo protegido, esta diferença não foi significativa $(p<0,05)$. Neste ciclo, as primeiras capturas ocorreram entre o final de outubro e o início de novembro (Figura 1). Os picos populacionais foram observados nos meses de fevereiro e março, o que coincidiu com a presença de bagas em pré-maturação e maturação (Figura 1). Nestes meses, os picos populacionais alcançaram o número de cinco MAD, indicando que a entrada das moscas-das-frutas nos vinhedos ocorre principalmente neste período. Nas avaliações feitas após a colheita, não foram observadas capturas (Figura 1).

No segundo ano de avaliação (ciclo 2006/07), houve redução significativa na quantidade de adultos da mosca-das-frutas capturados durante o ciclo, totalizando 135 e 94 insetos nas áreas com e sem cobertura, respectivamente. Neste ciclo, foi observada maior captura na área coberta $(+30,4 \%)$, porém sem diferença significativa $(\mathrm{p}<0,05)$. Esta redução total na população de moscas está relacionada, possivelmente, com a ocorrência de geadas na região, nos dias 4; 5 e 6-09-06 (Mandelli, 2007), as quais comprometeram a produção de fruteiras precoces nesta safra, reduzindo a oferta de ameixas e pêssegos. Isto pode ter limitado a oferta de hospedeiros alternativos que proporcionam a multiplicação desta espécie, assim como também pode ter afetado diretamente na morte dos insetos, o que resultou no decréscimo da população de moscas nas áreas observadas (Salles, 1995).

Durante o período avaliado do ciclo de 2006/07, em nenhum momento os picos populacionais alcançaram um MAD (Figura 1). Apesar da redução no número de insetos capturados, houve similaridade nos períodos de infestação, coincidindo com os mesmos picos do ciclo de 2005/06. As primeiras capturas de mosca-das-frutas ocorreram no início de novembro, passando por um período sem captura até a primeira quinzena de janeiro, quando a população aumentou. Este aumento, assim como no ciclo de 2005/06, também coincidiu com o período de maturação da videira, não existindo capturas após a colheita das uvas.

Nos experimentos com cobertura plástica, geralmente se observa uma aceleração no início da brotação em função do aumento da temperatura, antecipando a maturação das bagas na área coberta (Chavarria, et al.(2009). Mesmo com o conhecimento deste fato, neste trabalho não foi observada 
uma antecipação na captura das moscas na área coberta.

Mutwiwa et al. (2005) estudaram a influência de diferentes coberturas plásticas na infestação e distribuição de mosca-branca (Hemiptera: Aleyrodidae) na cultura do pimentão, em cultivo protegido. Estes autores observaram que onde foi utilizado plástico com absorção de radiação ultravioleta, houve menor infestação da praga, em comparação com plástico sem absorção, destacando a importância da luz ultravioleta na mobilidade deste grupo de insetos e os efeitos de diferentes coberturas plásticas como táticas de controle em programas de manejo integrado de pragas. No caso deste experimento com moscadas-frutas, foi observado que a cobertura plástica utilizada é uma barreira fotosseletiva para os comprimentos de ondas analisados, porém possui absorção média de $45 \%$ da luz no intervalo de comprimento de onda que varia de 300 a $580 \mathrm{~nm}$ (Tabela 2). Apesar desta diferença, não houve interferência na mobilidade das moscas pela presença da cobertura plástica, o que possivelmente pode estar relacionado com o tipo de plástico utilizado neste experimento (que não restringe na totalidade nenhum comprimento de onda) ou devido a esta espécie pertencer a um grupo de insetos que utiliza compostos químicos para sua orientação na procura de alimento e/ou hospedeiros (Sugayama \& Malavasi, 2000).
O cultivo protegido da videira tem permitido a produção de uvas orgânicas, já que se vislumbra a possibilidade de abandonar o uso de fungicidas sintéticos (Chavarria et al., 2007b). Dessa forma, a incidência da mosca-das-frutas em área de vinhedo com cobertura plástica indica a necessidade de medidas de ação quando a população ocorrer em níveis que possam causar dano econômico. Neste intuito, é importante considerar o uso de métodos aceitos em sistemas orgânicos de produção, como o uso de iscas tóxicas (Sislegis, 2008), o que se torna chave na certificação e comercialização da uva.

Em áreas com cobertura plástica em que se aplica o manejo fitossanitário convencional (uso de defensivos sintéticos), existe a possibilidade de incremento de resíduos nas frutas. Chavarria et al (2007a) observaram incremento de até 33\% no resíduo de fungicidas de princípio ativo captan em áreas cobertas. Este comportamento pode ser distinto para inseticidas, mas destaca-se esta possibilidade pelo fato de a cobertura restringir radiação ultravioleta e a ação da chuva sobre os produtos aplicados, o que pode alterar o tempo de carência dos princípios ativos registrados para a cultura (Agrofit, 2007). Apesar de este estudo ter sido realizado em uvas para processamento, o uso da cobertura plástica é mais abrangente em uvas destinadas ao consumo in natura (Chavarria et al., 2007a). Dessa maneira, problemas relacionados ao aumento de resíduos de agrotóxicos em fruteiras tomam maior proporção e devem ser levados em consideração no planejamento

dos tratamentos fitossanitários.

TABELA 1 - Médias diárias das observações microclimáticas, em vinhedo da cultivar Moscato Giallo, conduzida em "Y" com cobertura plástica (C) e descoberto (D), no ciclo 2005/06 e 2006/07. Flores da Cunha-RS.

\begin{tabular}{|c|c|c|c|c|c|}
\hline \multirow{2}{*}{$\begin{array}{l}\mathrm{V} \text { a } \mathrm{r} \text { i á } \mathrm{v} \text { e i s } \\
\text { microclimáticas }\end{array}$} & \multicolumn{2}{|c|}{$2005 / 2006$} & \multicolumn{2}{|c|}{$2006 / 2007$} & \multirow{2}{*}{ Equações de regressão $* * *$} \\
\hline & Coberta & Descoberta & Coberta & Descoberta & \\
\hline $\begin{array}{l}\text { Temp. máx. } \\
\left({ }^{\circ} \mathrm{C}\right)\end{array}$ & 31,94 & 28,19 & 31,80 & 30,37 & $\begin{array}{l}\mathrm{C}=4,51+0,897 \mathrm{D} \quad(\mathrm{P}=0,0005)^{* *} \\
\mathrm{R}^{2}=0,74\end{array}$ \\
\hline Tmédia $\left({ }^{\circ} \mathrm{C}\right)$ & 21,28 & 20,28 & 21,91 & 21,84 & $\begin{array}{l}\mathrm{C}=1,37+0,960 \mathrm{D} \quad(\mathrm{P}=0,0265) \\
\mathrm{R}^{2}=0,95\end{array}$ \\
\hline Tmín $\left({ }^{\circ} \mathrm{C}\right)$ & 14,70 & 14,50 & 16,33 & 16,07 & $\begin{array}{l}\mathrm{C}=0,64+0,972 \mathrm{D} \quad(\mathrm{P}=0,0012) \\
\mathrm{R}^{2}=0,94\end{array}$ \\
\hline UR $(\%)$ & 83,20 & 82,51 & $*$ & $*$ & $\begin{array}{l}C=13,2+0,848 D \quad(P<0,0001) \\
R^{2}=0,89\end{array}$ \\
\hline $\begin{array}{l}\text { RFA }\left(M J \cdot m^{-2} .\right. \\
\left.\operatorname{dia}^{-1}\right)\end{array}$ & 5,38 & 7,98 & 4,32 & 7,63 & $\mathrm{C}=0,629 \mathrm{D}$ \\
\hline $\mathrm{VV}\left(\mathrm{m} \cdot \mathrm{s}^{-1}\right)$ & 0,09 & 0,904 & 0,08 & 0,82 & $\begin{array}{l}\mathrm{C}=0,107 \mathrm{D} \\
\mathrm{R}^{2}=0,49\end{array}$ \\
\hline
\end{tabular}

*ausência de dados devido a problemas nos sensores (termopares de bulbo úmido). ** probabilidade de o coeficiente angular ser igual a 1 dos dois anos agrícolas em conjunto, pois não houve diferença significativa no comparativo entre anos agrícolas. Tmáx - temperatura máxima; Tméd - temperatura média; Tmín - temperatura mínima; UR - umidade relativa; RFA - radiação fotossinteticamente ativa; VV - velocidade do vento. 
TABELA 2 - Percentual de interceptação da radiação incidente (comprimento de onda) pela cobertura plástica sobre o dossel vegetativo de vinhedo da cultivar Moscato Giallo, medida com espectrorradiômetro comparado ao cultivo convencional. Flores da Cunha-RS.

\begin{tabular}{ccccccc}
\hline UV* $^{*}$ & Azul* & Verde* & Vermelho* & Vermelho distante* & Radiação total & $\begin{array}{c}\text { Relação } \\
\text { V:VD*** }\end{array}$ \\
\hline $56,18 \mathrm{a}^{* *}$ & $49,08 \mathrm{~b}$ & $44,85 \mathrm{~b}$ & $39,24 \mathrm{c}$ & $33,77 \mathrm{~d}$ & $45,09 \mathrm{~b}$ & 0,917 \\
\hline
\end{tabular}

*UV - ultravioleta $(300-390 \mathrm{~nm})$, azul (450-490 nm), verde (490-580 nm), vermelho - V (620-700 nm) e vermelho distante - V:D (700-750 nm). **Médias seguidas de letras distintas diferem entre si, ao nível de significância de 5\%, de acordo com teste de Tukey. ***valor da relação de incidência de radiação na faixa do vermelho (V) e vermelho distante (VD).

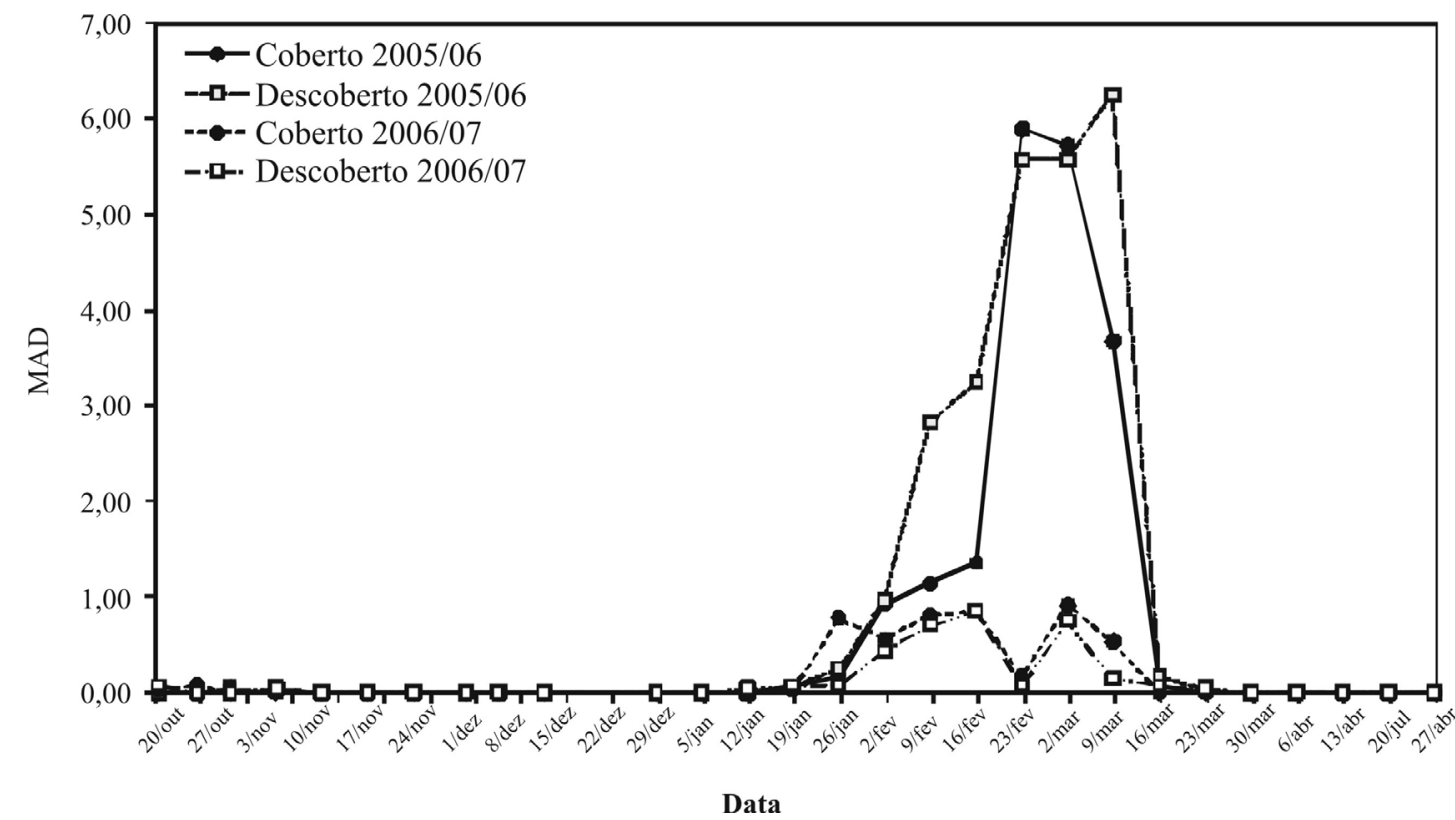

FIGURA 1 - Flutuação populacional de adultos de Anastrepha fraterculus em armadilhas McPhail iscadas com proteína hidrolisada (BioAnastrepha ${ }^{\circledR}$ a $5 \%$ ), em vinhedos da cultivar Moscato Giallo com e sem cobertura plástica, nas safras de 2005/2006 e 2006/2007, no município de Flores da Cunha-RS.

\section{CONCLUSÃO}

As condições microclimáticas propiciadas pela cobertura plástica no cultivo de videira não afetam a mobilidade e a flutuação populacional da Anastrepha fraterculus.

\section{AGRADECIMENTOS}

Os autores agradecem ao assistente de Pesquisa da Embrapa Uva e Vinho, Vanderlei Natal Gomes, à estagiária Cristiane Müller, à Terra Toledo Coberturas, ao CNPq e à Vinícola Giacomin, pelo auxílio na realização deste trabalho.

\section{REFERÊNCIAS}

AGROFIT: Ministério da Agricultura Pecuária e Abastecimento. Disponível em: $<$ http://extranet.agricultura.gov.br/agrofit_cons/principal_agrofit_cons $>$. Acesso em: 01 jun. 2007.

BARROS, R.; DEGRANDE, P.E.; SORIA, M.F.; RIBEIRO, J.S.F. Desequilíbrio biológico do ácarorajado Tetranychus urticae Koch, 1836 (Acari: Tetranychidae) após aplicações de inseticidas em algodoeiro. Arquivos do Instituto Biológico, São Paulo, v.74, n.2, p.171-174, 2007.

BOTTON, M.; HICKEL, E.R.; SORIA, S.J. Pragas. In: FAJARDO, T.V.M. (Ed.). Uva para processamento: fitossanidade. Brasília: Embrapa Informação Tecnológica, 2003. p.82-105. (Frutas do Brasil, 35) 
BRASIL. Ministério da Agricultura Pecuária e Abastecimento. Instrução Normativa no $\mathbf{7}$, de 17 de maio de 1999. Disponível em: $<$ http://extranet.agricultura. gov.br/sislegis-consulta/consultarLegislacao.do $>$. Acesso em: 01 mai.2008.

CARDOSO, L.S.; BERGAMASCHI, H.; COMIRAN, F.; CHAVARRIA, G.; MARODIN, G.A.B.; DALMAGO, G.A.; SANTOS, H.P.; MANDELLI, F. Alterações micrometeorológicas em vinhedos pelo uso de coberturas de plástico. Pesquisa Agropecuária Brasileira, Brasília, v.43, n.4, p.441-447, 2008.

CHAVARRIA, G.; SANTOS, H.P.; MANDELLI,F.; MARODIN, G.A.B; H.; CARDOSO, L.S. Caracterização fenológica e requerimento térmico da cultivar Moscato Giallo sob cobertura plástica. Revista Brasileira de Fruticultura, v. 31, p. 119-126, 2009.

CHAVARRIA, G.; SANTOS, H.P.; SÔNEGO, O.R.; MARODIN, G.A.B.; BERGAMASCHI, H.; CARDOSO, L.S. Incidência de doenças e necessidade de controle em cultivo protegido de videira. Revista Brasileira de Fruticultura, Jaboticabal, v.29, n.3, p.477-482, 2007a.

CHAVARRIA, G.; SANTOS, H.P.; SÔNEGO, O.R.; MARODIN, G.A.B.; BERGAMASCHI, H.; CARDOSO, L.S.; SCHNEIDER, E.P. Cultivo protegido: uma alternativa na produção orgânica de videira. Revista Brasileira de Agroecologia, Porto Algre, v.2, p.628 - 632, 2007 b.

DUARTE, A.L.; MALAVASI, A.; Tratamentos Quarentenários. In: MALAVASI, A.; ZUCCHI, R. A. Moscas-das-frutas de importância econômica no Brasil: conhecimento básico e aplicado. Ribeirão Preto: Holos, 2000. p.187-192.

GARCIA, F.R.M.; CORSEUIL, E. Análise faunística de moscas-das-frutas (Diptera, Tephritidae) em pomares de pessegueiro em Porto Alegre, Rio Grande do Sul. Revista Brasileira de Zoologia, Curitiba, v.15, n.4, p.1111-1117. 1998.

GARCIA, F.R.M.; CORSEUIL, E. Influência de fatores climáticos sobre moscas-das-frutas (Diptera: Tephritidae) em pomares de pessegueiro em Porto Alegre, Rio Grande do Sul. Revista da Faculdade de Zootecnia, Veterinária e Agronomia, Uruguaiana, n.1, p.71-75, 1999.

KOVAlESKI, A.; RIBEIRO, L.G. Manejo de pragas na produção integrada de maçãs. Bento Gonçalves: Embrapa Uva e Vinho, 2002. 7p. (Circular Técnica, 34).

MANDELLI, F. Comportamento meteorológico e sua influência na vindima de 2007 na Serra Gaúcha. Bento Gonçalves: Embrapa Uva e Vinho, 2007. p.1-6. (Comunicado Técnico, 76)

MELLO, L.M.R. de. Atuação do Brasil no mercado vitivinícula mundial - Panorama 2006: artigos técnicos. Bento Gonçalves: EMBRAPA/CNPUV, 2007. Disponível em: <http://www.cnpuv.embrapa. br/publica/artigos/panorama 2006vitivinicultura.pdf >. Acesso em: 01 nov. 2007.

MUTWIWA, U.N.; BORGEMEISTER, C.; VON ELSNER, B.; TANTAU, H.J. Effects of UV- absorbing plastic films on greenhouse whitefly (Homoptera: Aleyrodidae). Journal of Economic Entomology, Lanham. v.98, n.4, p.1221-1228, 2005.

R. Development Core Team. R: A language and environment for statistical computing. R. Foundation for statistical computing. Vienna, Áustria. Disponível em: < http://www.r-project.org/ > . Acesso em: 01 dez. 2007.

RAGA, A.; SOUZA FILHO, M.F. DE; SATO, M.E.; CERÁVOLO, L.C. Dinâmica populacional de adultos de moscas-das-frutas (Diptera: Tephritidae) em pomar de citros de Presidente Prudente-SP. Arquivos Instituto Biológico, São Paulo, v.63, n.2, p.23-28, 1996.

RONCHI-TELES, B.; SILVA, N.M. DA. Flutuação populacional de espécies de Anastrepha Schiner (Diptera: Tephritidae) na região de Manaus-AM. Neotropical Entomology, Piracicaba, v.34, n.5, p.733-741, 2005.

SALLES, L.A.B. Bioecologia e controle da moscadas-frutas sul-americana. Pelotas-RS: Embrapa CPACT, 1995.58 p.

SALLES, L.A.B. Principais pragas e seu controle. In: RASEIRA, M.C.B.R. (Ed.). A cultura do pessegueiro. Brasília: Embrapa-SPI; Pelotas: EmbrapaCPACT, 1998. p.205-242.

SANTOS, H.P. Fruteiras de clima temperado em cultivo protegido: desafios e perspectivas em vi- 
deira e macieira. In: SEMINÁRIO DE PESQUISA SOBRE FRUTEIRAS DE CLIMA TEMPERADO, 1., 2005, Bento Gonçalves. Programa e resumos... Bento Gonçalves-RS: Embrapa Uva e Vinho, 2005. 44p. (Documentos, 52).

SCHUCK, E.; CALIARI, V.; ROSIER, J.P. Uso da plasticultura na melhoria da qualidade de frutas. In: ENCONTRO NACIONAL SOBRE FRUTICULTURA DE CLIMA TEMPERADO, 7., 2004, FraiburgoSC. Anais...Caçador, SC: Epagri, 2004. 290p.

SELA, S.; NESTEL, D.; PINTO, R.; NEMNYLAVY, E.; BAR-JOSEPH, M. Mediterranean fruit fly as a potential vector of bacterial pathogens. Applied and Environmental Microbiology, Washington, n. 71, 4052-4056, 2005.

SORIA, S. de J. A mosca-da-fruta e seu controle. Bento Gonçalves: EMBRAPA-CNPUV,1985. 3 p. (Comunicado Técnico, 3 )
SUGAYAMA, R.L.; MALAVASI, A. Ecologia comportamental. In: A. MALAVASI, A.; ZUCCHI, R.A. (Ed.). Moscas-das-frutas de importância econômica no Brasil: conhecimento básico e aplicado. Ribeirão Preto: Holos, 2000. 327p.

TAUFER, M.; NASCIMENTO, J.C. DO; CRUZ, I.B.M. DA; OLIVEIRA, A.K. DE. Efeito da temperatura na maturação ovariana e longevidade de Anastrepha fraterculus (Wied.) (Diptera: Tephritidae). Anais da Sociedade Entomológica do Brasil, Londrina. v.29, n.4, p.639-648, 2000.

ZART, M. Bioecologia de Anastrepha fraterculus (Wiedemann, 1830) (Diptera: Tephritidae) em videira. 2008. 73 f. Dissertação (Mestrado em Agronomia - Entomologia Agrícola) - Faculdade de Ciências Agrárias e Veterinárias, Universidade Estadual Paulista, Jaboticabal, 2008.

ZUCCHI, R.A. Taxonomia. In: MALAVASI, A.; R.A. ZUCCHI (Ed.). Moscas-das-frutas de importância econômica no Brasil: conhecimento básico e aplicado. Ribeirão Preto: Holos, 2000. 327p. 